\title{
Simulation Study on a Heat Pump System Using
} R744/R290 as Refrigerant

\author{
Xiaowei Fan ${ }^{1}$, Xianping Zhang, ${ }^{2,3}$ and Fengkun Wang ${ }^{1}$ \\ 1. School of Energy and Environment, Zhongyuan University of Technology, Zhengzhou 450007, China \\ 2. School of Chemical Engineering and Energy, Zhengzhou University, Zhengzhou 450001, China \\ 3. School of Civil Engineering, Henan Institute of Engineering, Zhengzhou 450007, China
}

\begin{abstract}
Based on the Chinese National Standards involving heat pump water heater and space heating system, performances of the R744/R290 subcritical heat pump system have been discussed and compared with those of the R22 system, which is widely used in heat pump systems in China nowadays. It can be indicated that R744/R290 mixture can work efficiently as a refrigerant for heat pumps with a large heat-sink temperature rise. When mass fraction of R290 is increased, discharge pressure is reduced. Under the nominal working condition, there is an optimum mixture mass fraction of 20/80 for R744/R290 under conventional condensation pressure. Both the heating $\mathrm{COP}_{h s}$ (coefficient of performance) and volumetric heating capacity are increased by about $12.62 \%$ and $34.24 \%$ respectively compared with those of R22 based system. But for the heat sink with a small temperature rise, R744/R290 system has poorer performances than R22 system. When heat transfer pinch point in evaporator and condensation processes is considered, the degree of superheat has a negative influence upon system performances under the given conditions.
\end{abstract}

Key words: Carbon dioxide, propane, subcritical heat pump, pinch point, $C O P$.

\section{Introduction}

As efficient and energy conservation means, heat pump has unique advantages for environmental protection and energy usage. Now, the mainly used refrigerants in China for heat pump applications are R22, R134a, R410A and R407C etc., of which R22 system holds the dominant position. These working fluids are all the Freons which should be phased out in the near future. It is ideal to use natural refrigerants to replace R22 in a long run. However, there has no any satisfactory natural refrigerant to substitute R22 even now. Therefore in this paper, a tentative research has been carried out and natural refrigerants R744 and R290 are selected as the potential components to form the competitive mixture to replace R22, due to their environmentally friendly property, and since the mixture can also overcome shortcomings of high

Corresponding author: Xiaowei Fan, Ph.D., research fields: heat pump system with environment friendship refrigerant, solar energy utilization technology. E-mail: xwfan@zzti.edu.cn. discharge pressure for pure R744 and flammability for pure R290 [1].

Kim et al. [2] investigated the performance of an auto-cascade refrigeration system using zeotropic refrigerant mixture of R744/R290. Niu and Zhang [3] proposed to replace R13 with R744/R290 of 71/29 mass fraction on a cascade refrigeration system. Kim et al. [4] studied the charge and circulation concentration of R744/R290 mixture of 75/25 and $60 / 40$ by the charged mass fraction in the subcritical air-conditioning system. Cho et al. [5] investigated the characteristics of evaporative heat transfer and pressure drop of R744/R290 mixtures of 75/25, 50/50, 25/75 mass fractions in horizontal and vertical smooth and micro-fin tubes. Sarkar and Bhattacharyya [6] have proposed blends R744/R600 and R744/R600a as working fluids in subcritical heat pumps for medium and high temperature heating fields. They concluded that blend R744/R600a can be the best alternative refrigerant to R114 for high temperature heating. The previous studies on the R744/R290 mixtures mainly 
aimed to the cascade refrigeration system or the cooling performance of system. However, the investigations on the heating performance for R744/R290 mixtures applied to heat pump system are scarce in the published literature.

Based on the previous researches on pure R744 heat pump by our research group, R744/R290 mixture is proposed as a potential alternative refrigerant used in heat pump systems for water heating and space heating [7]. Then it is essential to confirm which composition of mixture is optimum, or at least appropriate, for the certain heat pump application. Based on the Chinese National Standards involving in water heater and space heating system, the heating coefficient of performance, compressor power consumption, condensation pressure, compression ratio, discharge temperature, mass and volumetric heating capacities have been analyzed for different R744/R290 mixtures in the subcritical cycle. And the performance comparisons with that of R22 based system have been presented. Finally, the influences of superheat degree on performances of system using R744/R290 mixture as the working fluid have been studied for the optimum composition under the specific conditions.

\section{Method}

2.1 Mathematical Modeling of Subcritical Heat Pump System

Fig. 1 shows the schematic diagram of heat pump system using the mixture R744/R290 as refrigerant in a subcritical cycle. The corresponding temperature-entropy diagram is shown in Fig. 2.

In order to develop a model close to the practical cases, it is reasonable to take heat transfer temperature pinch point into consideration during evaporation and condensation. Due to zeotropic mixtures' unique characteristics of large non-linear variation of two-phase enthalpy against temperature during the phase change process, the distributed parameter model is used in this study which will provide a good agreement with the real conditions and therefore improve its prediction [8]. The heat exchanger is divided into a number of segments. Based on the mass continuity equations of working fluid and the secondary fluid, the outlet state of the former element is the inlet state of the latter element under the steady condition. For an element, lumped parameter approximation is employed to develop the model.

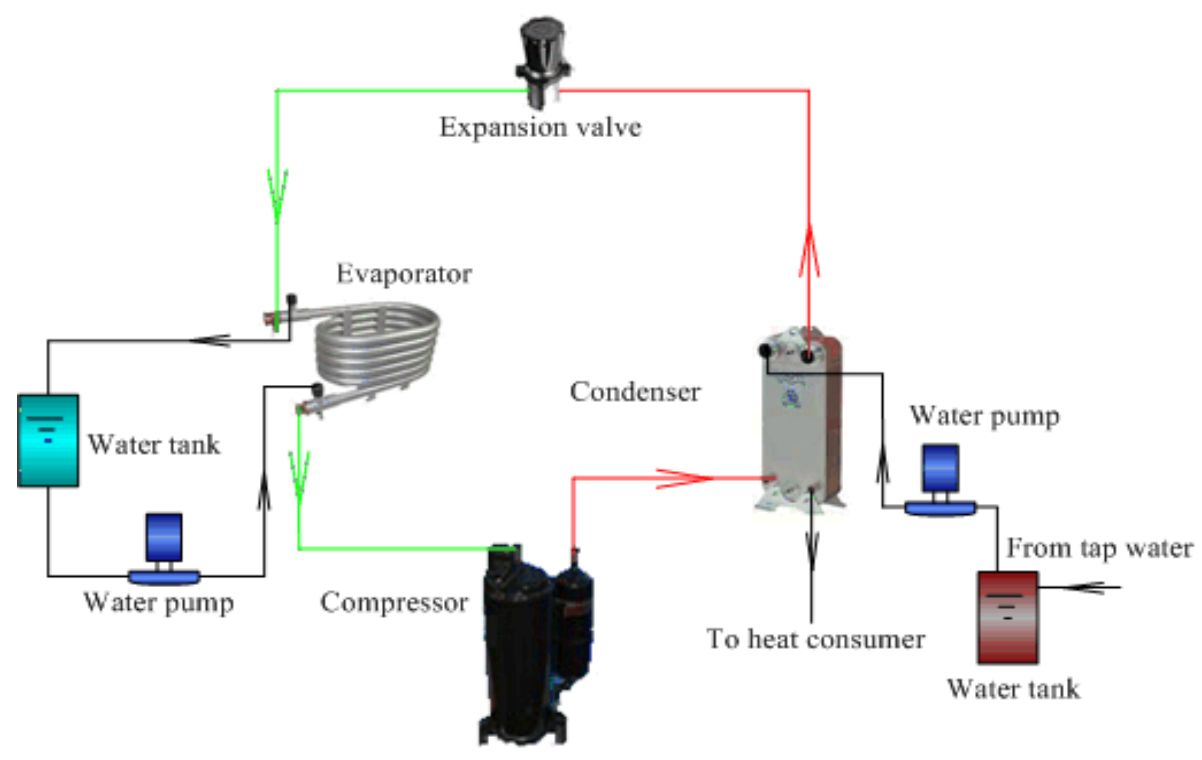

Fig. 1 Schematic diagram of R744/R290 based subcritical heating system. 


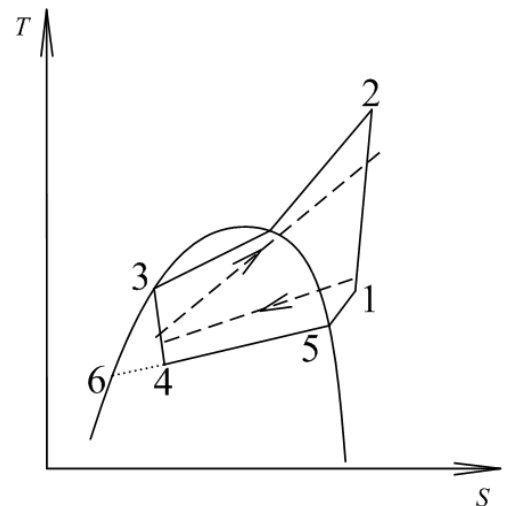

Fig. 2 T-s diagram showing the R744/R290 based subcritical heat pump.

In the evaporator, when inlet temperature of heat source is given, then the outlet temperature for fluid at point 1 is equal to inlet temperature of heat source minus designed pinch point temperature difference. If a certain value for pinch point is wanted, the outlet temperature for fluid at point 1 has to be iteratively determined using element method stated above. In the condenser, when inlet temperature of heat sink is given, then outlet temperature at point 3 is equal to inlet temperature of heat sink plus designed pinch point temperature difference. The pinch point can be controlled by the same method as what used in the evaporator. The element method can expect to develop more instructive results than the estimated method assuming that the R744 based mixtures have a linear curve of enthalpy with temperature during phase change.

\subsection{Simulation Conditions}

Based on the energy balance of individual components of the system, steady flow energy equations have been employed in each case. In order to simplify the analysis, the following assumptions have been made: the system operates at steady state; the R744 and R290 are all considered as the pure fluid, and the lubricant effect upon their properties or the mixtures properties is negligible; pressure drops in two heat exchangers and connecting pipes have been neglected; heat transfer between the system and the ambient are not taken into account. Compression process is adiabatic but non-isentropic and the isentropic efficiency of 0.70 is assumed for each case, evaporation process and heat rejection process for mixtures are isobaric, the pinch point temperature approaches for both evaporator and condenser are designed as a constant value of $7{ }^{\circ} \mathrm{C}$. Due to the neglect of heat transfer resistance, the pinch point is set to a value a little higher than the normal value of $5{ }^{\circ} \mathrm{C}$ for fear that heat transfer will deteriorate in practical case.

Based on the above analysis, a simulation code for subcritical R744/R290 heat pump systems using Engineering Equation Solver was developed [9]. The property subroutines in the code have been linked with an interface program EES_REFPROP which calls REFPROP to carry out the necessary property calculations [10-11].

\section{Results and Discussion}

\subsection{Water Heat Pump Application}

On the basis of the Chinese national standard GB/T23137-2008 [12], the heat sink and heat source temperatures are determined. The heat sink inlet and outlet temperatures are $15{ }^{\circ} \mathrm{C}$ and $55{ }^{\circ} \mathrm{C}$ while the heat source temperatures of different kind are shown in Table 1. The variation of R744/R290 performance with mass fraction of R290 for heat pump water heater application is shown in Fig. 3. As illustrated in Fig. 3, under the given working conditions, the minimum mass fractions of R290 should maintain between $21 \%-23 \%$ below which the mixture will have a lower critical temperature than $37{ }^{\circ} \mathrm{C}$ and therefore fails to

Table 1 Temperatures of different kinds of heat sources.

\begin{tabular}{llll}
\hline Heat source & $\begin{array}{l}\text { Water- } \\
\text { loop }\end{array}$ & $\begin{array}{l}\text { Ground- } \\
\text { water }^{\mathrm{b}}\end{array}$ & $\begin{array}{l}\text { Ground- } \\
\text { loop }^{\mathrm{c}}\end{array}$ \\
\hline Inlet temperature $\left({ }^{\circ} \mathrm{C}\right)$ & 20 & 15 & 10 \\
Outlet temperature $\left({ }^{\circ} \mathrm{C}\right)$ & 15 & 10 & 5 \\
\hline
\end{tabular}

a water-loop heat source is the circulated water in the public pipeline; ${ }^{b}$ ground-water heat source is the water from well, lake or lake; ' ground-loop heat source is the circulated water in the ground coil. 


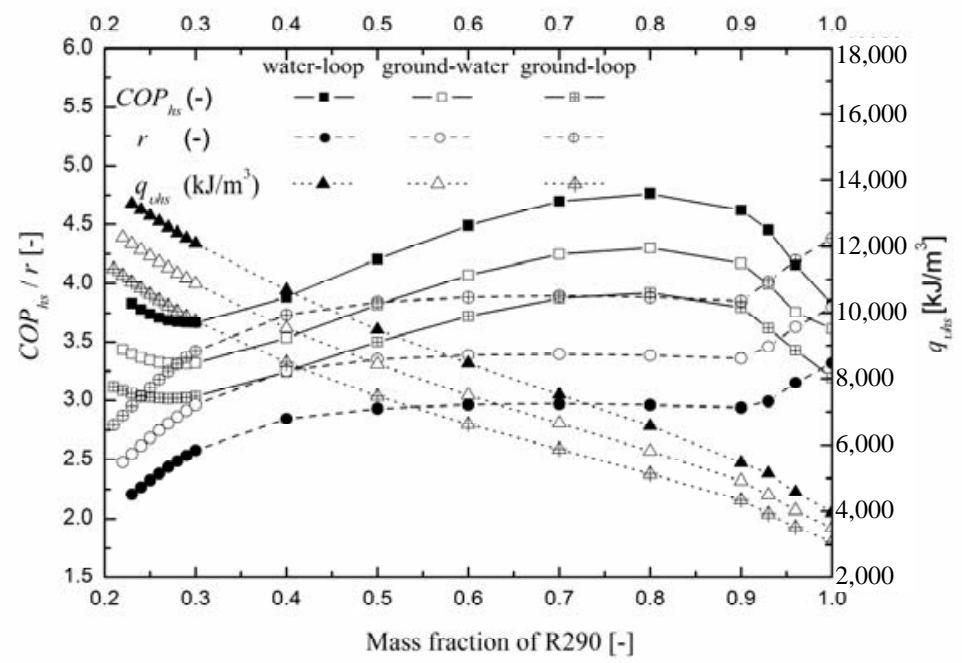

Fig. 3 Variation of R744/290 performance with mass fraction of R290 for water heater application.

obtain the higher heat sink outlet temperature of $55^{\circ} \mathrm{C}$ in subcritical cycle. Compressor ratio $r$ is increased gradually and gently as mass fraction of R290 is increased. The system performance shows the similar characteristics for different kinds of heat sources. Unless otherwise specified, the heat source in the following discussion is water-loop.

When heat source inlet temperature increases, $C O P_{h s}$ tends to rise because of the higher evaporation temperature. It may be seen that the $C O P_{h s}$ slightly decreases when the mass fraction of R290 increases in the beginning. The reason is that the ratio of specific heating capacity gain to specific heating capacity, $\Delta q_{h s} / q_{h s}$ is lower than that of compressor power, $\Delta w_{c s} / w_{c s}$. So $C O P_{h s}$ drops firstly. After the minimum point, they are going in the opposite direction. As shown in Fig. 4, the compressor power curve $w_{c s}$ shows a flat increase while the specific heating capacity $q_{h s}$ rises sharply, thus resulting an increase in $C O P_{h s}$. At the point of mass fraction R744/R290 of 20/80, $C O P_{h s}$ reaches a peak. Because mixture with different composition has different temperature glide characteristics during evaporation and condensation, under the given heat sink conditions, there must exist an optimum composition to achieve the optimum temperature matching between working fluid and the secondary fluids. Compared with the pure R290 based system, the mixture system has the higher volumetric heating capacity which is useful for system compactness.

As shown in Fig. 5, the discharge pressure of R744/R290 mixture $P_{c}$ is reduced when mass fraction of R290 is increased. The system can work with the optimum $\mathrm{COP}_{h s}$ for R744/R290 of 20/80 under the conventional condensation pressure of $2.573 \mathrm{MPa}$. It is clear that the compressor discharge temperature increases firstly and then decreases. All the temperature values are lower than that of R22, which guarantees a steady operation of compressor.

Table 2 presents the system properties under the identical conditions for R22 based system, and for comparison the corresponding properties of optimum composition of mixture are also listed in the table. For water-loop, ground-water and ground-loop heat sources, the $C O P_{h s}$ of R744/R290 mixture system are enhanced by $13.43 \%, 12.66 \%$ and $11.77 \%$, respectively. Furthermore, the volume heating capacities are increased by 33.49\%, 34.19\% and $35.04 \%$, respectively. Each of the three compressor discharge temperatures $t_{2}$ for mixture system is lower than the corresponding value of R22 based system under same condition, which makes the system work steady and durably. The condensation pressure $P_{c}$ and evaporation pressure $P e$ for mixture are all lightly 


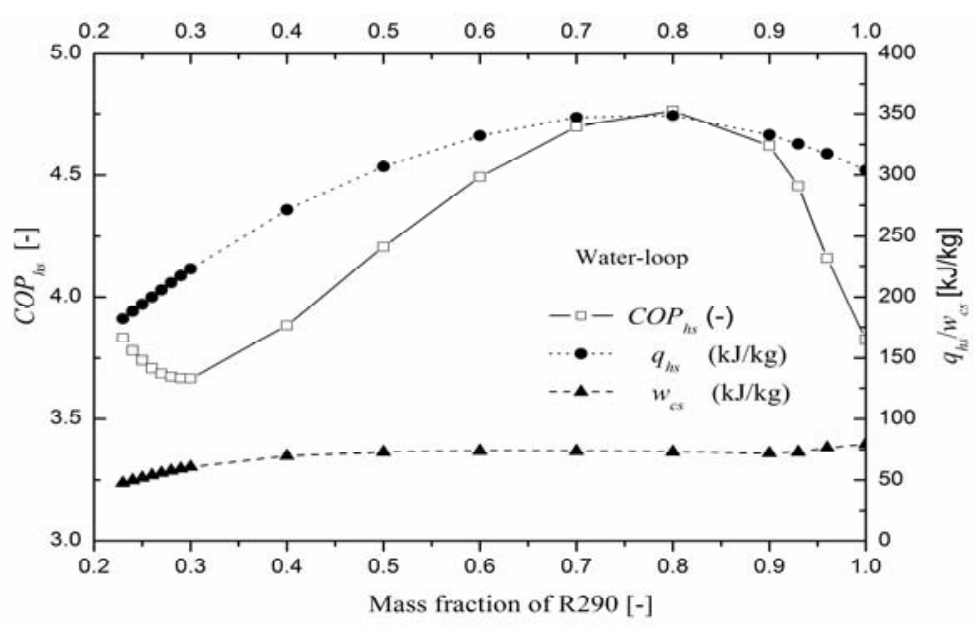

Fig. 4 Variation of R744/290 performance with mass fraction of R290 for water-loop water heater.

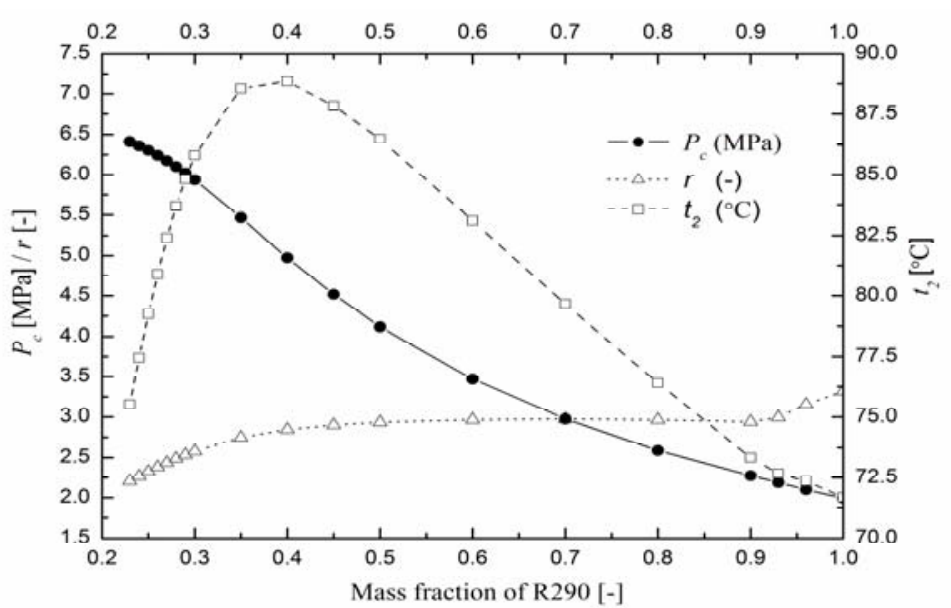

Fig. 5 Variation of $r$ and $t_{2}$ with mass fraction of R290 for water-loop water heater.

Table 2 Performance comparison for R22 and mixtures with optimum composition.

\begin{tabular}{|c|c|c|c|c|c|c|}
\hline \multirow{2}{*}{ Ref. Par } & \multicolumn{2}{|c|}{ Water-loop } & \multicolumn{2}{|c|}{ Ground-water } & \multicolumn{2}{|c|}{ Ground-loop } \\
\hline & $\mathrm{R} 22$ & $\mathrm{M}$ & R22 & $\mathrm{M}$ & R22 & $\mathrm{M}$ \\
\hline$C O P_{h s}(-)$ & 4.228 & 4.762 & 3.84 & 4.326 & 3.525 & 3.94 \\
\hline$q_{h s}(\mathrm{~kJ} / \mathrm{kg})$ & 181.6 & 349.1 & 186.1 & 355.5 & 190.8 & 362.3 \\
\hline$w_{c s}(\mathrm{~kJ} / \mathrm{kg})$ & 43.95 & 72.78 & 48.45 & 82.18 & 53.13 & 91.94 \\
\hline$q_{v h s}\left(\mathrm{~kJ} / \mathrm{m}^{3}\right)$ & 4,930 & 6,581 & 4,338 & 5,821 & 3,801 & 5,133 \\
\hline$P_{c}(\mathrm{MPa})$ & 2.139 & 2.573 & 2.115 & 2.547 & 2.086 & 2.521 \\
\hline$P_{e}(\mathrm{MPa})$ & 0.641 & 0.8734 & 0.548 & 0.7569 & 0.466 & 0.653 \\
\hline$r(-)$ & 3.338 & 2.946 & 3.857 & 3.365 & 4.472 & 3.862 \\
\hline$t_{2}\left({ }^{\circ} \mathrm{C}\right)$ & 87.1 & 76.03 & 90.88 & 77.99 & 94.74 & 80.07 \\
\hline
\end{tabular}

higher than those of R22 system. It can be concluded that R744/R290 with the optimum composition is a competitive alternative for R22.

\subsection{Space Heating Application}

Based on the national standard, the heat sink inlet and out temperatures are set to $40{ }^{\circ} \mathrm{C}$ and $45{ }^{\circ} \mathrm{C}$ which are the typical temperatures for space heating, and the heat source inlet and out temperatures are $15^{\circ} \mathrm{C}$ and $7{ }^{\circ} \mathrm{C}$ [13]. As that in water heater heat pumps, it is essential to provide a minimum R290 composition of about $40 \%$ under the given working conditions. The 
variation of R744/290 system performance with mass fraction of R290 is shown in Fig. 6. It can be seen that the $C O P_{h s}$ increases with the mass fraction of R290. But compared with the performance of pure R290 or R22 system showed in Table 3, the system using mixture has the poorer performance. The maximum $C O P_{h \text { s }}$ for $\mathrm{R} 744 / 290$ of $90 / 10$ is decreased by $9.48 \%$ in comparison with pure R22. However, one advantage of mixture system in such application is that its volumetric heating capacities are higher compared with R22. For R744/290 of 90/10 it is decreased by $8.19 \%$. Results clearly show that the zeotropic mixture $\mathrm{R} 744 / 290$ is not suitable for constant space heating application. So the following statements focus on the water heater applications.
3.3 Influence of Superheat Degree for Optimum Fraction

The influence of superheat degree on the system performance is highly dependent on the working fluid used and the specified conditions. An appropriate degree of superheat can protect compressor from hammering by liquid refrigerant. It is still good for system performance for some refrigerants, but harmful for some other refrigerants. As analyzed above, the R744/290 mixture fraction of 20/80 is optimum. Under the given conditions in this paper for optimum fraction, the influences of superheat degree on the system performance are illustrated in Fig. 7. As the degree of superheat increases, both the $C O P_{h s}$ and the

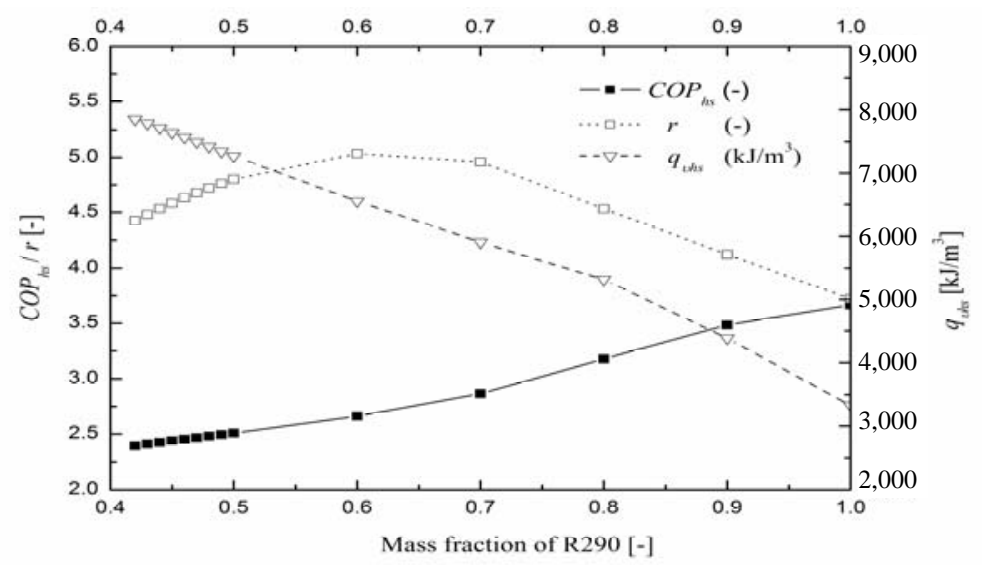

Fig. 6 Variation of R744/290 performance with mass fraction of R290 for space heating application.

Table 3 System performances for $\mathrm{R} 22$ space heating system.

\begin{tabular}{llllllll}
\hline Ref & $C O P_{h s}(-)$ & $q_{h s}(\mathrm{~kJ} / \mathrm{kg})$ & $w(\mathrm{~kJ} / \mathrm{kg})$ & $q_{v h s}\left(\mathrm{~kJ} / \mathrm{m}^{3}\right)$ & $P_{c}(\mathrm{MPa})$ & $r(-)$ & $t_{2}\left({ }^{\circ} \mathrm{C}\right)$ \\
\hline $\mathrm{R} 22$ & 3.84 & 190.3 & 49.56 & 4,040 & 1.976 & 3.97 & 89.0 \\
\hline
\end{tabular}

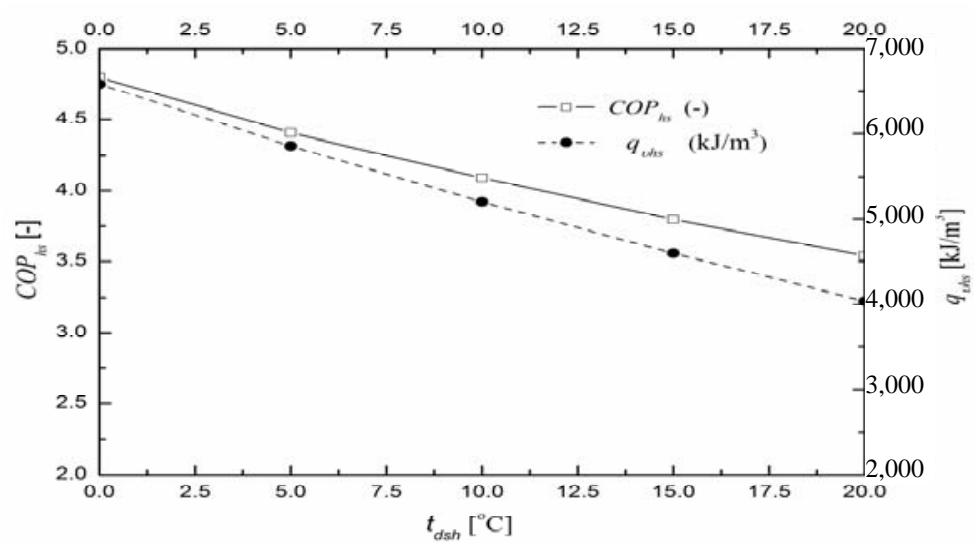

Fig. 7 Effect of degree of superheat on the R744/290 subcritical system performance. 
volumetric heating capacity tend to decrease. The reason is that in order to guarantee the designed pinch point between working fluid and secondary fluid, the mean evaporation is decreased as the degree of superheat is increased. So it is suggested that the R744/290 mixture system would work with a basic degree of superheat only to defend compressor from hammering.

\section{Conclusions}

For the subcritical cycles, R744/R290 mixtures are more efficient in heat pumps with a large heat-sink temperature rise, e.g., high-temperature water heater system, and superior system performances can be obtained compared with R22. The heat pump using R744/R290 mixture of 20/80 has the maximum $C O P_{h s}$ which is enhanced by about $12.62 \%$ comparison with R22 system. Meanwhile, the unit volumetric heating capacity is enhanced by about $34.24 \%$. Other advantages of this application are lower compression ratio, discharge temperature compared with that R22, and lower heat rejection pressure compared to pure R744. For heat sink with a small temperature glide such as space heating, heat pump using R744/R290 mixtures has poorer performances than that using R22. In order to obtain a high outlet temperature of $55{ }^{\circ} \mathrm{C}$ for heat sink, the mass fraction of R290 should not be less than $21 \%$ for subcritical cycles.

\section{Acknowledgments}

This work was supported by the National Natural Science Foundation of China (No. 51176207), Henan Province Project for the Excellent Youth Scholars of Higher Education of China (No. 2012GGJS-185), Key Project Foundations of the Science and Technology Committee of Henan Province (No. 122102310617), Henan Province Education Department Natural Science Project (No. 2010B560003) and Doctoral Scientific Fund Project of Henan Institute of Engineering (No. D2012006).

\section{References}

[1] J.H. Kim, J.M. Cho, M.S. Kim, Cooling performance of several $\mathrm{CO}_{2}$ /propane mixtures and glide matching with secondary heat transfer fluid, Int. J. Refrig. 31 (5) (2008) 800-806.

[2] S.G. Kim, M.S. Kim, Experiment and simulation on the performance of an autocascade refrigeration system using carbon dioxide as a refrigerant, Int. J. Refrig. 25 (8) (2002) 1093-1101.

[3] B.L. Niu, Y.F. Zhang, Experimental study of the refrigeration cycle performance for the R744/R290 mixtures, Int. J. Refrig. 30 (1) (2007) 37-42.

[4] J.H. Kim, J.M. Cho, I.H. Lee, J.S. Lee, M.S. Kim, Circulation concentration of $\mathrm{CO}_{2} /$ propane mixtures and the effect of their charge on the cooling performance in an air-conditioning system, Int. J. Refrig. 30 (1) (2007) 43-49.

[5] J.M. Cho, Y.J. Kim, M.S. Kim, Experimental studies on the characteristics of evaporative heat transfer and pressure drop of $\mathrm{CO}_{2}$ /propane mixtures in horizontal and vertical smooth and micro-fin tubes, Int. J. Refrig. 33 (1) (2010) 170-179.

[6] J. Sarkar, S. Bhattacharyya, Assessment of blends of $\mathrm{CO}_{2}$ with butane and isobutane as working fluids for heat pump applications, Int. J. Therm. Sci. 48 (7) (2009) 1460-1465.

[7] X.P. Zhang, X.W. Fan, F.K. Wang, H.G. Shen, Theoretical and experimental studies on optimum heat rejection pressure for a $\mathrm{CO}_{2}$ heat pump system, Appl. Therm. Eng. 30 (16) (2010) 2537-2544.

[8] P.G. Zhao, L. Zhao, G.L. Ding, C.L. Zhang, Temperature matching method of selecting working fluids for geothermal heat pumps, Appl. Therm. Eng. 23 (2) (2003) 179-195.

[9] S.A. Klein, Engineering Equation Solver, Academic Commercial Version 8.889, Wisconsin Madison, 2011.

[10] EES_REFPROP Inerface, NIST (National Institute of Standards and Technology), USA, 2010.

[11] E.W. Lemmon, M.L. Huber, M.O. McLinden, Reference Fluid Thermodynamic and Transport Properties (REFPROP), NIST Standard Reference Database 23, Version 8.0, 2010.

[12] GB/T23137-2008, Heat Pump Water Heater for Household and Similar Application, China. (in Chinese)

[13] GB/T18430.1-2007, Water Chilling (Heat Pump) Packages Using the Vapor Compression Cycle-Part 1: Water Chilling (Heat Pump) Packages for Industrial and Commercial and Similar Application, China. (in Chinese). 